\title{
Pathological Studies on Infectious Bronchitis Disease in Chickens
}

\author{
Moustafa S. Abou El-Fetouh ${ }^{1}$, Mohamed H. Mohamed ${ }^{1}$, Nahla A.G. Refat ${ }^{1}$, Mohamed H. \\ Ahmed $^{2}$, Abd Elfattah I. El-Zanaty ${ }^{2 *}$ \\ ${ }^{1}$ Pathology Department, Faculty of Veterinary Medicine, Zagazig University, 44511, Egypt \\ ${ }^{2}$ Poultry Diseases Department, Animal Health Research Institute, Dokki, Giza, Egypt
}

\begin{abstract}
Infectious bronchitis virus has been recognized as highly contagious disease in chickens. In this study, 138 birds from 10 broiler chicken flocks that suffered from respiratory disease were examined to study the pathological lesions associated with IBV infection in naturally infected flocks. Moreover, the infection was confirmed via virus isolation and PCR. Samples were harvested from both Sharkia and Gharbia provinces during one year (October 2014-2015). The clinical examination of the investigated birds showed nasal discharges, gasping and rales. Congested trachea with lumen contained mucus and caseated material at the biforcation of the two main bronchi were characteristic in most of the necropsied birds. The kidneys were enlarged and dark red or pale with the presence of whitish precipitate in the ureters. Four isolates recovered from four different broilers chicken's flocks were further analyzed by S1 glycoprotein gene sequencing. The phylogenetic analysis of the deduced amino acids sequences of the four strains revealed that they were closely related to the IBV Egyptian variant 2 and IS/1494/2006 strains. The histopathological examination of the kidneys showed focal aggregation of lymphocytes in the renal cortex and the medulla. The liver showed multiple focal areas of necrosis which replaced by lymphocyte and heterophils aggregation. The spleen showed thickened capsule with subcapsular hemorrhage and mild to severe focal depletion of lymphocytes. Trachea, lungs, proventriculus, intestine and bursa showed hyperplasia and degenerative changes in their epithelium. Blood vessels showed endotheliosis with perivascular edema and leukocyte infiltration in various organs. Edema was also seen in heart, trachea and lungs. Finally, it could be concluded that infectious bronchitis virus is a major cause and strongly implicated in respiratory and/or renal problems of the Egyptian broiler chicken flocks. Moreover, Egyptian variant 2 still evolving and causing severe damage to renal tissue and various organs.
\end{abstract}

Keywords: Infectious bronchitis virus, Variant, Broiler, RT-PCR, Pathology.

\section{Introduction:}

Infectious bronchitis virus (IBV) is a gamma coronavirus in the subfamily Coronavirinae and family Coronaviridae. It has a great economic effect on poultry industry, because it causes extensive damage to a wide range of epithelial surfaces in various parts of the body [1].

Infectious bronchitis virus strains vary greatly in their tissue tropism, they may cause respiratory syndrome, with clinical signs being gasping, rales, coughing, or sneezing with or without nasal discharges [2]. In addition, nephropathogenic lesions may occur causing acute to chronic nephritis, urolithiasis and mortality. After apparent recovery, chronic nephritis can produce death at a later time, also, it has been reported that the virus can produce disease of the proventriculus [3].
In Egypt, infectious bronchitis disease was initially recorded by Ahmed in 1954 [4], also, different studies have reported the disease during the last few years [5-12]. The objective of this work was to study the pathological lesions associated with infectious bronchitis virus infection in naturally infected broiler chicken flocks and to characterize IBV field isolates from Sharkia and Gharbia Governorates.

\section{Material and methods}

\section{Examined birds}

In this study, pooled samples from 10 broiler chicken farms at Sharkia and Gharbia Governorates were collected during October 2014 to October 2015. The birds had a history of previous vaccination with IBV vaccines (IB primer or $\mathrm{H} 120$ at one day old and MA5 at

*Corresponding author e-mail: (abdelfattahelzanaty@gmail.com), Poultry Diseases Department, 
about 14 days old). The selected farms showed mild to moderate respiratory signs that were recorded during the study. Necropsy was also performed and gross lesions were reported.

\section{Sampling and specimens' collection}

Tissue samples (Trachea, bronchi, lungs, proventriculus, cecal tonsils and kidneys) were collected from the examined birds for virus isolation and identification. Specimens from trachea, lungs, kidneys, proventriculus, liver, heart, spleen, bursa, cecal tonsil and intestine were fixed in neutral buffered formalin $10 \%$ for histopathological examination.

Preparation of samples for IBV detection and isolation

The collected organs were washed in sterile saline, and then the tissue homogenates $(10 \%$ $\mathrm{w} / \mathrm{v})$ were suspended in sterile saline $(0.85 \%$ $\mathrm{w} / \mathrm{v})$. By disrupting the organs using sterile mortar and pestle, the homogenates were centrifuged at $3000 \mathrm{rpm}$ for $10 \mathrm{~min}$. The supernatant was treated with $10000 \mathrm{IU} / \mathrm{mL}$ penicillin, $1.0 \mathrm{mg} / \mathrm{mL}$ streptomycin. The samples were then examined for the presence of IBV using RT-PCR and virus isolation [13].

\section{Virus isolation}

Specific pathogen free (SPF) embryonated chicken eggs (9-11 days old) were used for inoculation of the prepared samples via the allantoic sac route $(0.1 \mathrm{~mL}$, each ). Additional two passages were performed from the harvested allantoic fluids. Allantoic fluids and chorioallantoic membranes (CAM) were harvested aseptically 48 hours postinoculation. On 18 days old embryo, all survived embryos were removed from the incubator and placed at $4^{\circ} \mathrm{C}$ for $18-24$ hours. Embryos were then examined for the presence of IBV infection [14].

\section{Agar Gel Preciptation Test (AGPT)}

Noble agar $1.5 \%$ in saline was prepared for AGPT, the homogenate of the CAM of infected chicken embryos $(\mathrm{Ag})$ was prepared then tested by agar gel priciptation test (AGPT) against standard hyperimmune serum against IBV. Hyperimmune serum against IBV was kindly provided by Dr. Mohammed Hussein ,Animal Health Research Institute and was prepared in chickens according to Mahmoud et al. [15].

\section{Reverse Transcriptase Polymerase Chain Reaction (RT-PCR)}

Tissue homogenate (trachea, lungs, kidneys, cecal tonsils and proventriculus) supernatants were pooled and sent to Reference Laboratory of Veterinary Quality Control on Poultry Production (RLQP). The hyper variable region of spike 1 gene (HVR-3) was amplified by RT- PCR using primers (Metabion, Germany) designed by RLQP and the sequence of the primers are: Forward IBVF 21299: 5' - TCA GAG TGG TTA TTA TAA TT- ' 3 and Reverse IBV- R 21702: 5'- CTG CCA TAT ATA TTA TAC TC- '3. The viral RNA was extracted using QiaAmp viral RNA mini kits (Qiagen, $\mathrm{GmbH}$, and Hilden, Germany) following the manufacturer's instruction.

Amplification was carried out using Qiagen one step RT-PCR Kit (Qiagen, GmbH, and Hilden, Germany). The reaction conditions were reverse transcription at $50^{\circ} \mathrm{C}$ for $30 \mathrm{~min}$, primary denaturation at $95^{\circ} \mathrm{C}$ for $15 \mathrm{~min}$ followed by 40 cycles of denaturation at $95^{\circ} \mathrm{C}$ for $30 \mathrm{sec}$., annealing at $54^{\circ} \mathrm{C}$ for $45 \mathrm{sec}$ and extension at $72^{\circ} \mathrm{C}$ for $2 \mathrm{~min}$, and finally a final extension at $72^{\circ} \mathrm{C}$ for $10 \mathrm{~min}$. RT-PCR product was visualized by Electrophoresis in $1.5 \%$ agarose in IX TAE, ethidium bromide was added to a concentration of $0.5 \mu \mathrm{g} / \mathrm{mL}$ for nucleic acid visualization [16].

\section{Purification of DNA and sequence reaction}

Six samples were randomly chosen for sequencing. The amplicons were purified using the QIA quick gel extraction kit (Qiagen, $\mathrm{GmbH}$, and Hilden, Germany). The sequence reactions were performed using genetic analyzer Applied Biosystems 3130 (ABI, USA) by Big Dye Terminator V3.1 cycle sequencing kit. (Perkin, Elmer, Foster city, CA). Sequences similarities and relationships of the HVR-3 of the S1gene from the 6 samples in this study were compared with previously published IBV vaccine and reference strains available in the GenBank (NCBI, United States) (http://www.ncbi) [17].

Amino acids phylogenetic tree was drawn for the sequenced isolates along with other vaccine and reference strains available in the GenBank database using MEGA version 6 [18]. A comparative analysis of deduced 
amino acids and nucleotide sequences of the HVR-3 was created using the CLUSTAL W Multiple Sequence Alignment program, version 1.83 of MegAlign module of Lasergene DNAStar software [19]. The phylogenetic tree analysis was conducted by neighbor -joining method using bootstrap analysis (1000 replications) using Mega 5 software.

The sequenced isolates were submitted to the GenBank and accession numbers of KU728159 (IBV/EG/GHARBIA-F729-32015) and KU728160 (IBV/EG/SHARQIAF729-4-2015) for classical strains, KU728161 (IBV/EG/GHARBIA-F248-3-2015),

KU728162 (IBV/EG/GHARBIA-F248-42015), KU728163 (IBV/EG/GHARBIA-F2488-2015) and KU728164 (IBV/EG/GHARBIAF248-9-2015) for variant strains were obtained.

\section{Pathological examination}

Specimens were processed using the paraffin histopathological technique. Paraffin sections of about five microns thickness were prepared and stained with hematoxylin and eosin and they examined microscopically [20].

\section{Results}

\section{Clinical signs}

Chickens showed mild to moderate respiratory signs as well as diarrhea. Respiratory signs included nasal discharges, gasping, runny and/ or red eye, swelling of the head, rales and sneezing.

\section{Gross lesions}

The post mortem examination of the examined birds showed emaciated and dehydrated carcasses, besides the presence of whitish pasty material at the vent. Some chickens showed facial swelling and edema with the presence of serous or mucus or viscid material at the nares and nasal passages.

The tracheas were congested and the lumen contained clear to turbid mucous exudate of different amount. Some bronchi showed the presence of caseated material at bronchial biforcation. In some flocks, the caseous material partially or completely obliterated the bronchial lumen (Figure 1-a). Lungs showed dark red colour areas with frothy exudate, while, other lung specimens showed pale firm consolidated areas. The kidneys were raised, enlarged, dark red or pale in colour with the presence of whitish precipitate (urates) in the ureters (Figure 1-b). The proventriculus was slightly enlarged, nodular and thick. Liver was congested, dark coloured with slightly enlarged size. In some cases, the heart showed turbid serous membranes (Figure 1-c). The spleen and bursa were slightly increased in size, while, the cecal tonsils and intestine showed slightly congested blood vessels. 

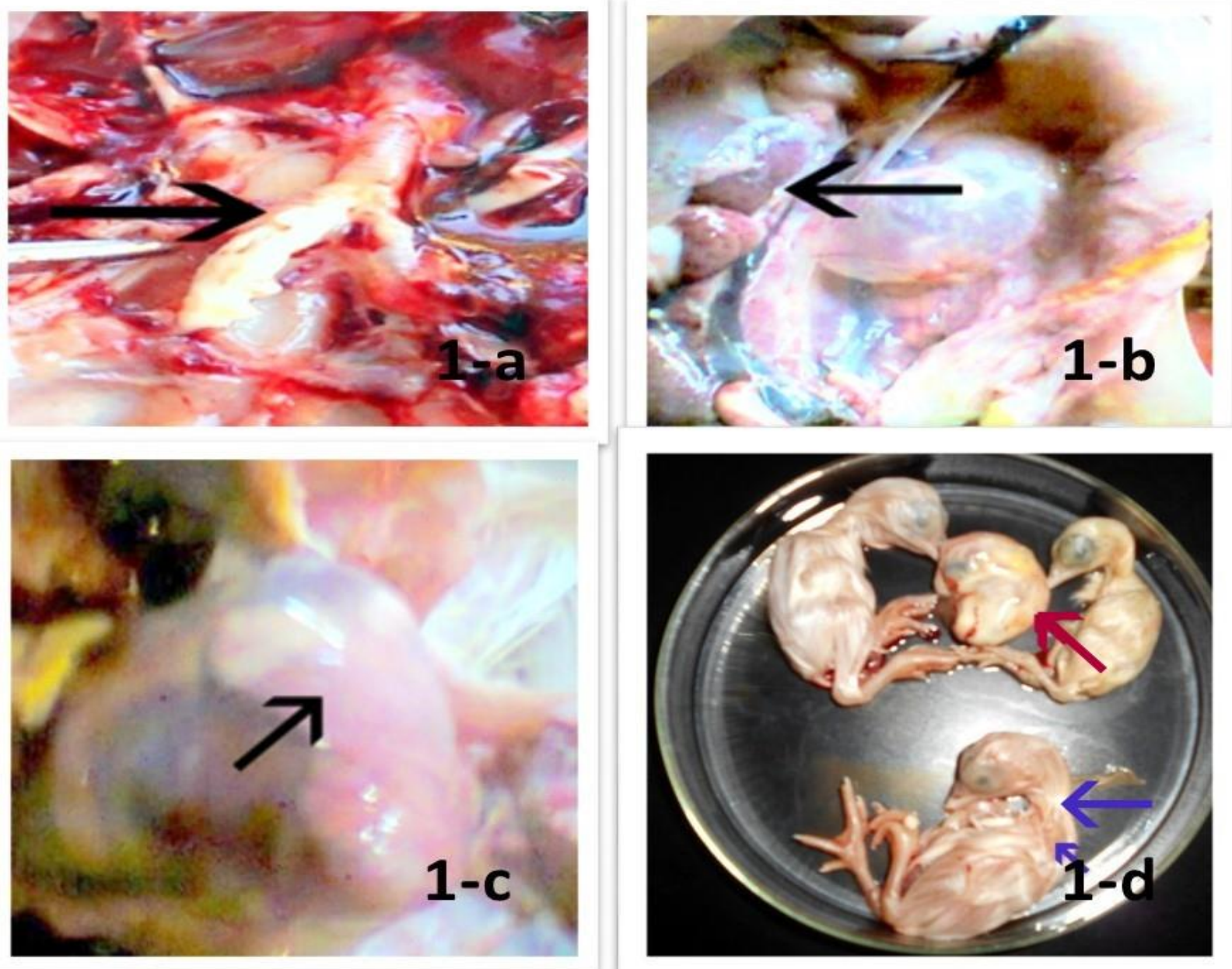

Figure 1: Broiler chicken of 29 days old (a): Bronchi showed caseous material obliterating the bronchial lumen (arrow). (b): kidney, enlarged dark red kidneys and hemorrhage (arrow). (c): The heart showing turbid serous membranes (arrow). (d): Embryos 18 days showing dwarfing and curling (red arrow) and control (blue arrow).

\section{Virological findings}

\section{Embryonated chicken eggs}

The examined embryos at 18 days showed dwarfing and curling, (Figure 1-d) and urates deposition in mesonephrons

\section{Agar gel precipitation test}

The virus infected CAM showed white line precipitate in AGPT against specific hyperimmune serum of IB virus.

\section{S1 gene amplification and sequencing}

All the tested 10 pooled samples were positive by RT-PCR, they showed specific bands at 400 base pair. Six samples were randomly selected for sequencing. The analysis for the sequence data obtained from the nucleotide sequence of the HVR3 in S1 gene and protein were performed to determine the difference among the six isolates. It was conducted to estimate the similarity percent for HVR3 in S1 protein of IBV strains and to compare the isolates with other reference and vaccinal strains published in the GenBank database (Table 1). 
Table 1: The identity percent and divergence for HVR3 in S1 protein of isolated infectious bronchitis virus strains compared with other reference and vaccinal IBV strains published in the GenBank database

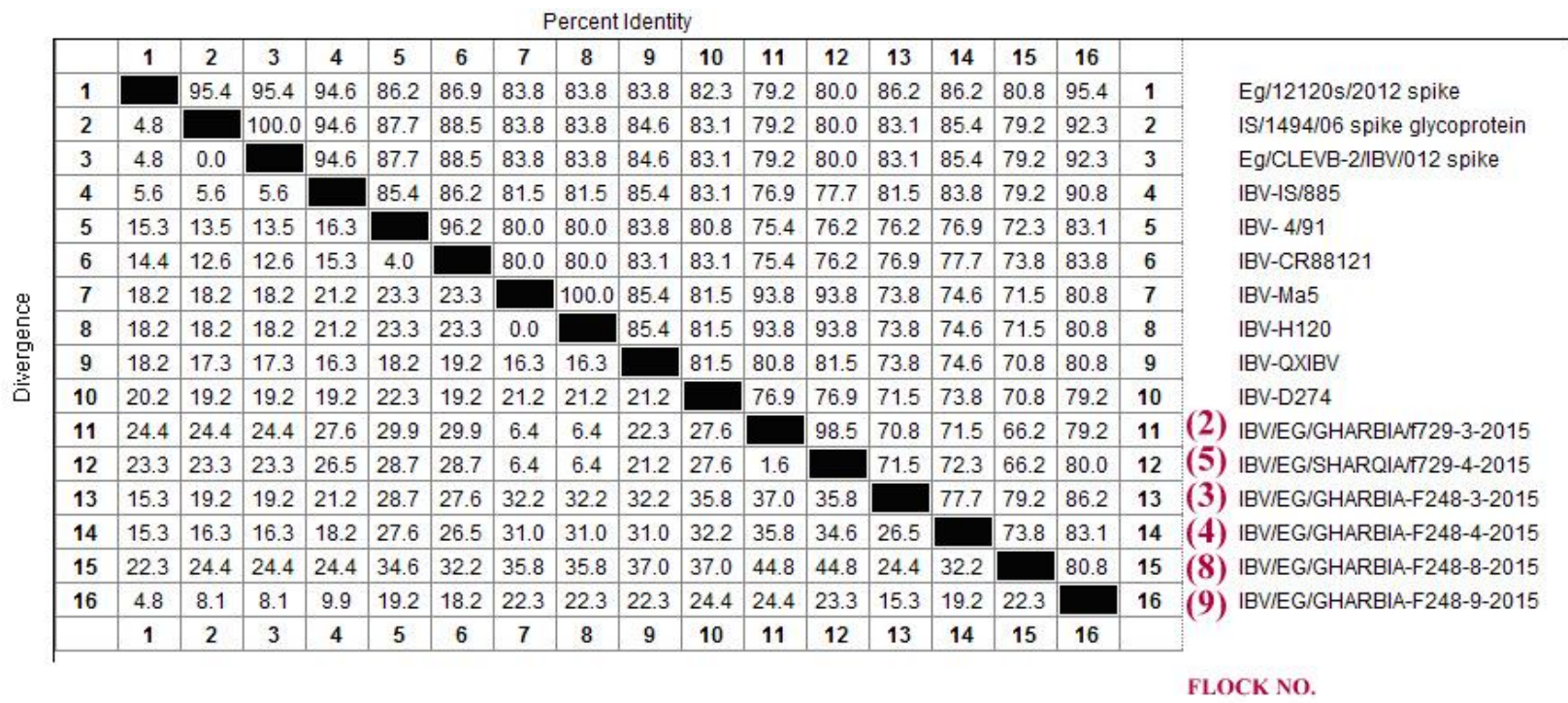

The phylogenetic tree was constructed from amino acids sequence of $\mathrm{S} 1$ protein to assess the genetic relationship among the IBV field isolates with other reference and vaccinal strains published in the GenBank database (Figure 4). The six isolates were separated into two distinct groups, four isolates $(3,4,8,9)$ were found closely related to IBV variant $2-$ like strain (IS/1494/2006) and two isolates (2, 5) were closely related to IBV classical strains of IBV (H120 like vaccinal strain and CK/CH/LSD/121228) (Figure 2). The classical isolates $(2,5)$ had amino acids sequence identity $98.5 \%$ with each other. They shared $66.2-80 \%$ of amino acids sequence with the variant isolates. They shared $93.8 \%$ of amino acids sequence with classic vaccinal strains (H120 and Ma 5). While, the identity percent with the vaccinal strain were 4/91(75.476.2\%); CR88 (75.4-76.2\%) and D274 $(76.6 \%)$. The variant isolates $(3,4,8$, and 9) were found to be closely related to Egyptian Var. 2 and other related strains in the GenBank. They shared each other by $73.8-86.2 \%$. They shared the Egyptian variants Eg/12120s / 2012 spike (80-95.4\%) and Eg/CLEVB-2/IBV012 spike (79.2-92. 3\%).Also they were related to IS/1494/06 (79.2-92.3\%) and IS/885 (79.2-90. $8 \%)$. They were related to vaccinal strains used in Egypt 4/91 (72.3-83.1\%), CR88121 (73.8$83.8 \%)$, D274(70.8-79.2\%) and QX strain $(70.8-80.8 \%)$. They shared $(71.5-80.8 \%)$ of amino acids sequence with classic vaccinal strains (H120 and Ma 5). The main amino acid mutation in the S1 (HVR 3) were as at Q30S, L51I, R81L, T88S and N123F in classical strains, while, at Q30V, Q30H, Y102F and $\mathrm{N} 123 \mathrm{Y}$ in variant -2 strains.

\section{Histopathological findings}

The lining epithelium of the trachea was hyperplastic and showed metaplasia. The tracheal lumen contained sloughed, desquamated epithelium with few granulocytes (Figure 3-a). Tracheal submucosa was edematous with mild to moderate lymphocyte infiltration. The serosal blood vessels showed endotheliosis (Figure 3-b). The lungs showed congestion, hemorrhage and edema with thickening of the interalveolar tissue (Figure 3c). Interstitial pneumonia with fibroblastic cell proliferation were recorded. The bronchial epithelium showed desquamation, necrotic masses and bronchiolitis. The renal tissue showed focal aggregation of lymphocytes in the cortex and the medulla with hypercellularity of some glomeruli associated with perivascular and interstitial haemorrhage (Figure 3-d). The renal tubules showed desquamation, degeneration of the lining epithelium and peritubular edema (Figure 3-e). Some renal tubules contained few tubular hyaline casts, and there was also inter tubular hemorrhage and congestion. 


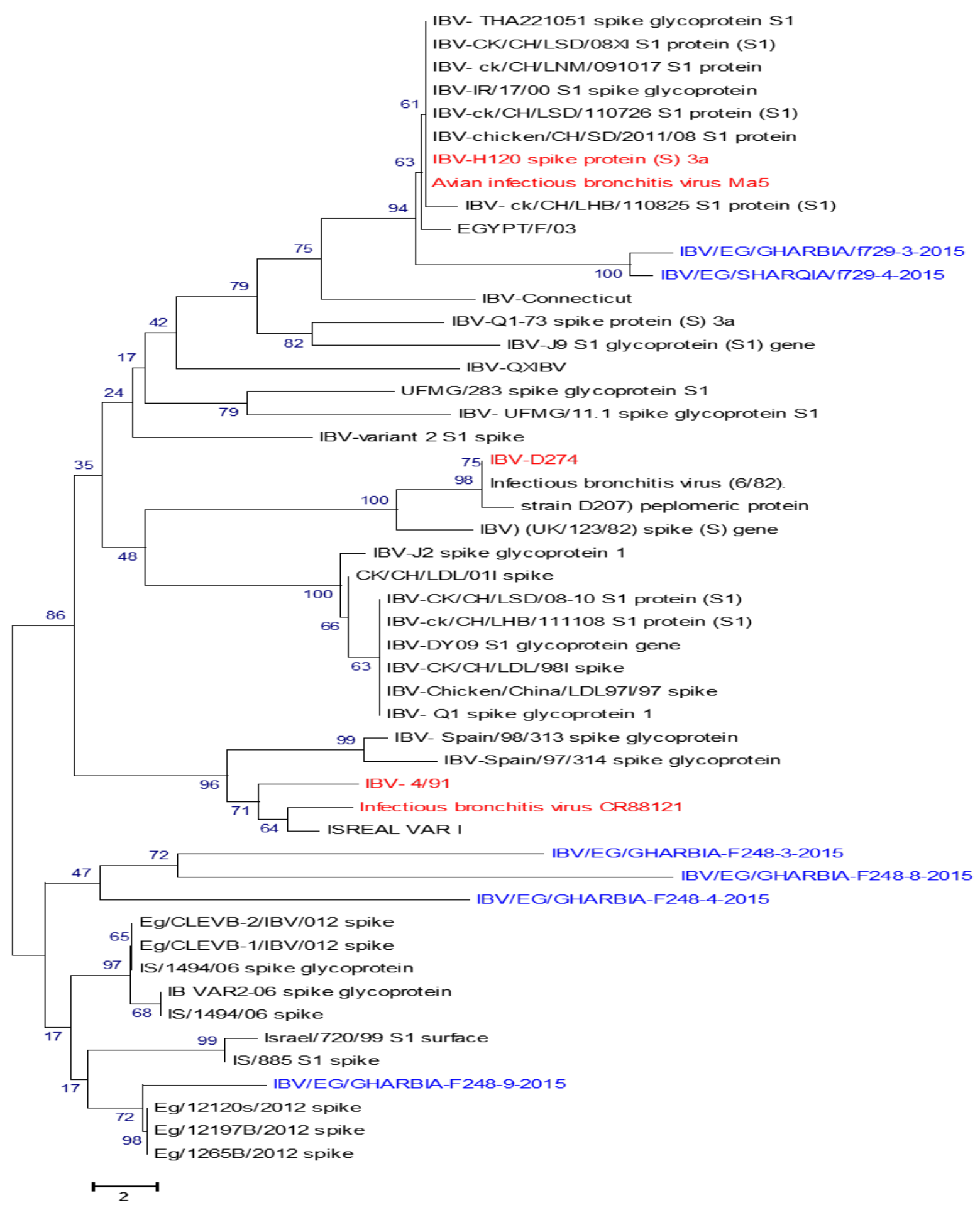

Figure 2: Phylogenetic tree of the 400 bp fragment of the S1 amino acids sequence of the six Egyptian IBV isolates in this study (blue color), vaccinal strain present in Egypt (red color) and other reference IBV strains. The phylogenetic tree analysis was conducted by neighbor -joining method using bootstrap analysis (1000 replications) using Mega 5 software. 

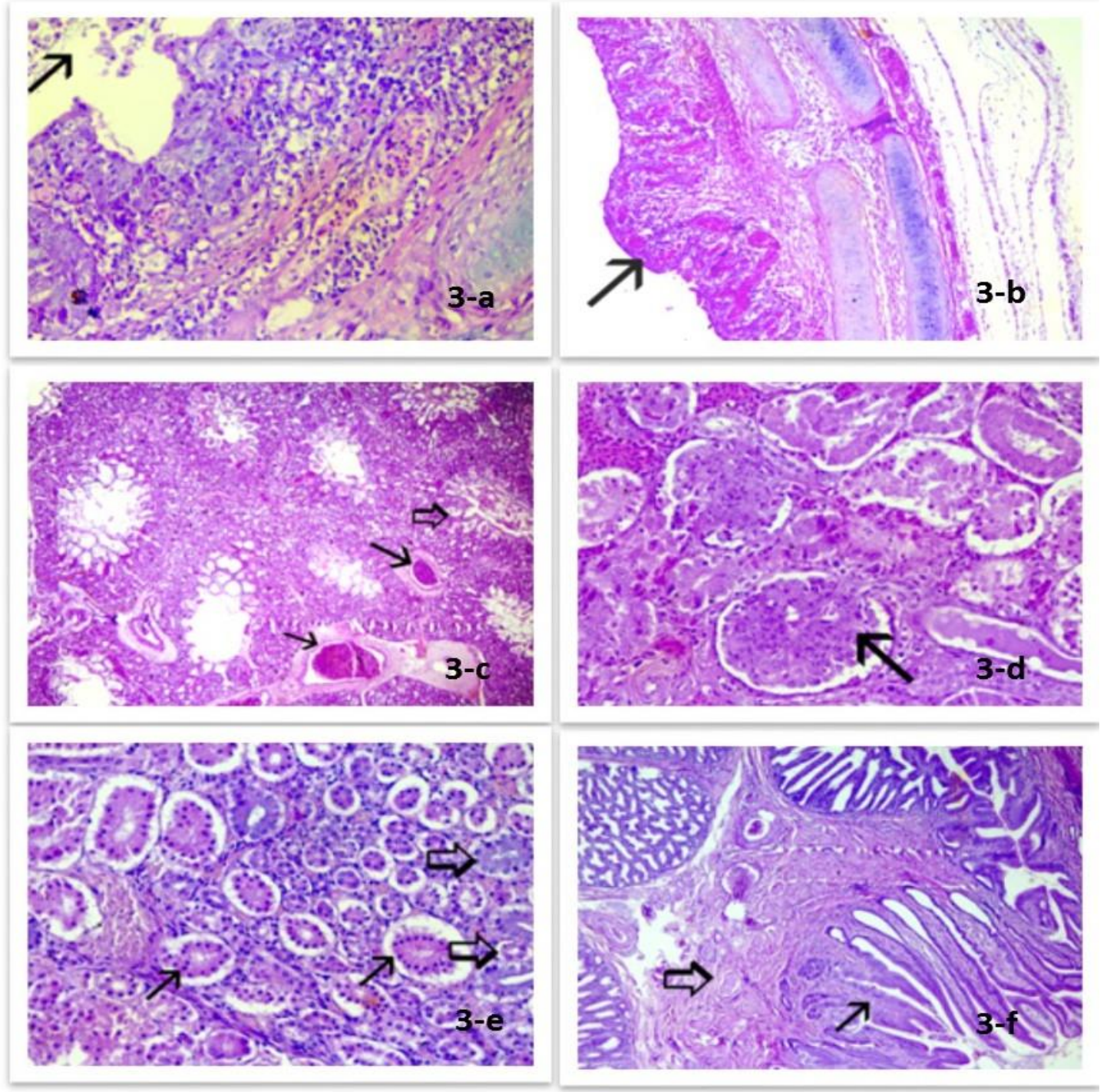

Figure 3: (a): Trachea showing desquamated epithelium (arrow). HE. X1200. (b): Trachea showing thickening epithelium (arrow) with congested blood vessels. HE. X 300. (c): Lung showing congestion (arrow) thickening of interalveolar tissue with hemorrhage, edema and few lymphocytes (hollow arrow). HE. X 300 . (d): Kidneys showing congestion of peritubular blood vessels, thickening of bowman's capsules and hyper cellularity of glomeruli (arrow). HE. X 1200. (e): Kidneys showing denudation (arrow) and necrosis of tubular epithelium represented by pyknotic nuclei (hollow arrow). HE. X 1200. (f): Proventriculus showing hyperplasia (arrow), degeneration of villar epithelium and connective tissue proliferation in sub mucosa (hollow arrow) HE. X 300.

The proventriculus showed hyperplasia and metaplasia with cyst formation of the lining epithelium. There was vacuolar degeneration and necrosis of some glandular epithelium. The sub mucosa showed congested blood vessels, edema, mononuclear cell infiltration and connective tissue proliferation (Figure 3f). Proliferation of glandular epithelium and hyperplasia associated with sloughed epithelium were observed (Figure 4-a). Edema and inflammatory cell infiltration in both lamina propria and the muscular layer were also noticed (Figure 4-b).

The hepatic tissue revealed multiple focal areas of necrosis which was replaced by lymphocyte and heterophils aggregation (Figure 4-c). The hepatocytes showed degenerative and fatty changes and the blood vessels were congested with perivascular edema and mononuclear cell infiltration. Some 
blood vessels contained micro thrombi and some of them were organized.

The cardiac tissue showed intermuscular edema with few leucocytic infiltrations (Figure 4-d), while, the spleen showed thick capsule, mild to severe focal depletion of lymphocytes from white pulp and mild focal sub capsular hemorrhages (Figure 4-e). Some blood vessels were congested and others showed thick wall. Bursal lining epithelium showed vacuolation, while, some follicles showed depletion of lymphocytes and necrosis which was
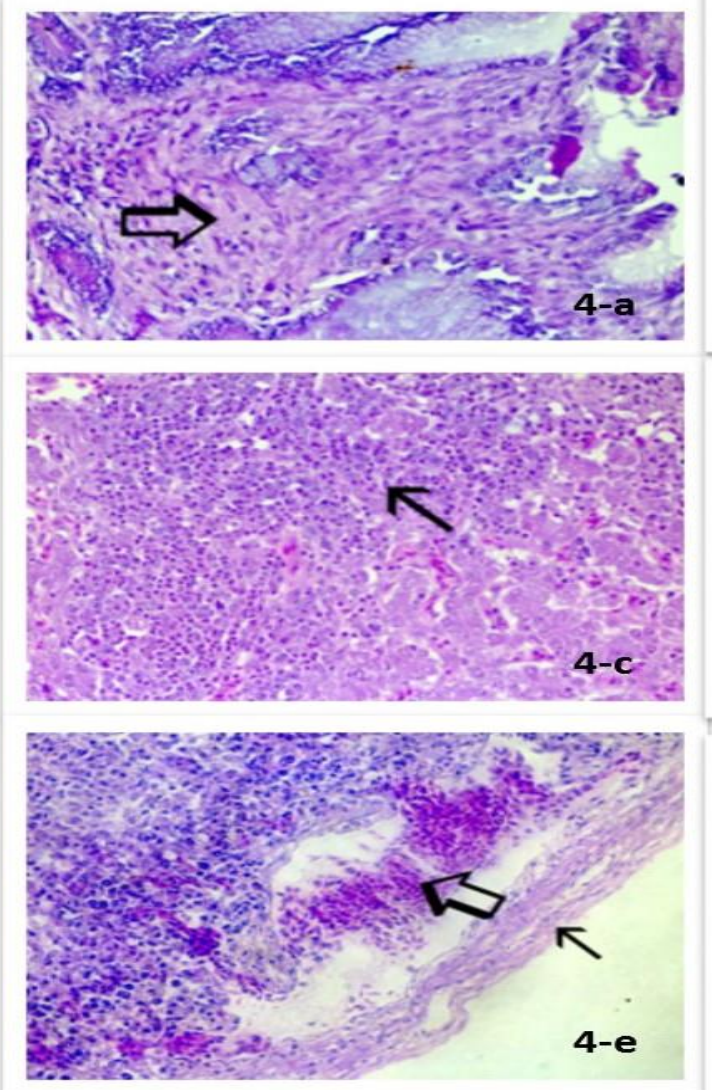

represented by pyknotic nuclei. Interfollicular edema was also seen (Figure 4-f).

The intestinal lining epithelium showed vacuolation, necrosis and desquamation. The glandular epithelium showed hyperplasia, cystic dilation with presence of esinophilic mass and leukocytes. The sub mucosa was infiltrated with lymphocytes, heterophils, macrophages and plasma cells. Lamina propria showed congested blood vessels and endotheliosis.
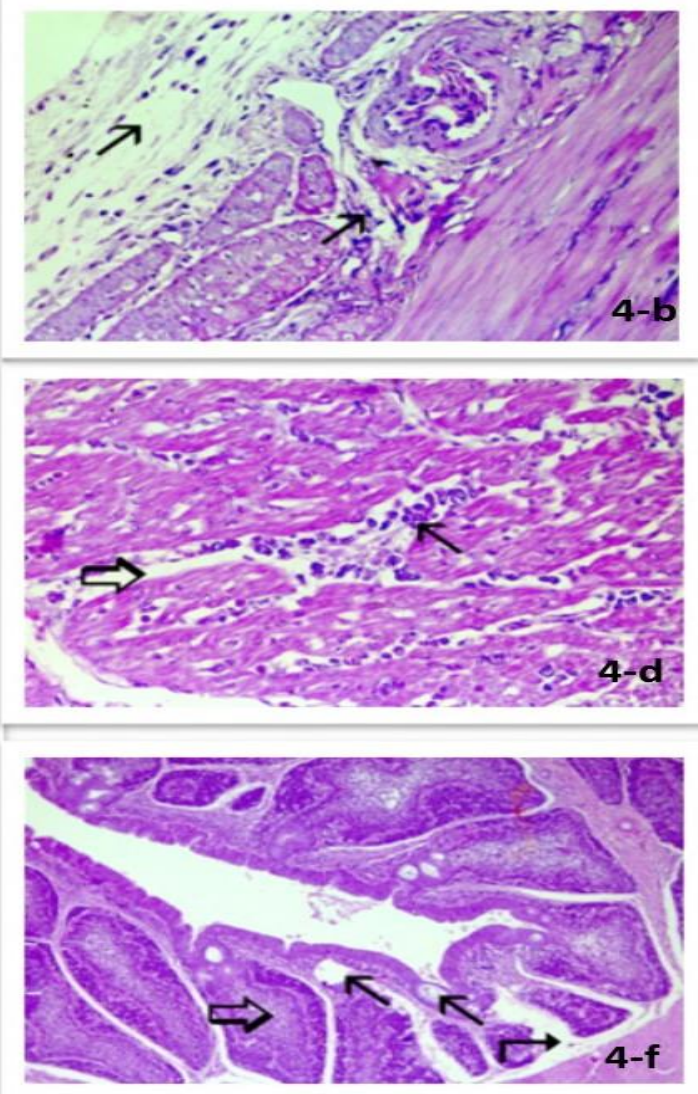

Figure 4: (a): Proventriculus high power of previous figure showing hyperplasia and connective tissue proliferation (hollow arrow). HE. X 1200. (b): Proventriculus showing inflammatory edema (arrow) and inflammatory cell infiltration in both lamina propria and muscular layer. HE.X 1200. (c): Liver showing focal area of necrosis which replaced by lymphocyte and heterophils aggregation (arrow). HE. X 300. (d): Heart showing intermuscular edema (hollow arrow) with few leucocytic infiltration (arrow) mainly heterophil. HE. X 1200. (e): Spleen showing thick capsule (arrow) and subcapsular hemorrhage (hollow arrow). HE. X 1200. (f): Bursa showing vacuolation of the lining epithelium (arrow), depletion of lymphocytes (hollow arrow) and interfollicular edema (broken arrow).HE. X 300.

\section{Discussion}

Infectious bronchitis virus is ubiquitous and characterized by high mutation rate. It has a large number of serotypes or genotypes all over the worldwide. Many countries have shown that multiple variant IBV strains were circulating in their poultry flocks [17].
Although IBV primarily affecting the respiratory tract, IBV demonstrates a wide range of tissues tropism, including the renal and reproductive systems and enteric form $[21,22]$.

In Egypt, since 2000 many IBV variants with nephropathogenic property was isolated and characterized [8,23-26]. The clinical signs 
and necropsy findings of the examined affected chickens were in agreement with the results obtained by El Shafey [7].

The specimens taken for IBV isolation must include trachea, lungs, kidneys and cecal tonsils as previously reported [26]. The use of CAM homogenate in agar gel precipitation test against positive reference sera gave specific positive precipitin band [13].

In our study, the partial sequencing and phylogenetic analysis of $400 \mathrm{bp}$ representing the HVR-3 of the S1 gene were conducted. The results revealed that these viruses were separated into two distinct groups; variant (variant 2) and classic. Meanwhile Zanaty et al. [27] isolated $20 \mathrm{IBV}$ viruses, 16 belonged to variant group and 4 belonged to classic group (Mass-like). The variant group was subdivided into 6 isolates (Egy /Var-1) and 10 isolates (Egy /Var -2). The IBV isolates in the variant group were grouped with other IBV strains from the Middle East. The variant group was likely resembling the original Egyptian variant strain (Eg/12120s/2012spike) and (Eg/CLEVB-2/IBV/012 spike) and the Israeli strains (IS/885/00), israel720/99 and (IS/1494/2006) [27].

The obtained isolates were related to the variant group of IBV with multiple mutations in HVR3, these results are in agreement with Hassan et al. [28].

The histopathological examination revealed that the kidneys showed focal aggregation of lymphocytes in the renal cortex and the medulla. Trachea, lungs, proventriculus, intestine and bursa showed hyperplasia and degenerative changes in their epithelium. These lesions of the trachea, lungs and kidneys were also observed by Mahdavi et al. [29].

In the trachea, IBV infection resulted in hypertrophy of goblet cells, rupture, and formation of excess mucus. The ciliated cells showed complete deciliation of the tracheal surface. Swelling and increase in the amount of endoplasmic reticulum was seen in infected birds by Seifi and Boroomand [30]. The specific histological lesions finding in all infected birds, exhibited tracheal lesions with mucosal thickening, hyperplasia of the surface epithelium, mononuclear inflammatory cell infiltrate of lamina propria. Primary and secondary bronchi, epithelial hyperplasia and mononuclear inflammatory cell infiltrate of the lamina propria were also observed by Khataby [31].

The bursa showed depletion of lymphocytes and necrosis but the bursal and thymus atrophy were associated with IBVs infection [32,33]. Proventriculus and intestine showed hyperplasia and degenerative changes in their epithelium. Proventriculus tunica propria was populated with lymphocytes and the intestine showed mild mononuclear cell infiltration in the mucous membranes in few cases, these finding were constant with those previously reported [34].

Blood vessels of the examined organs showed endotheliosis with perivascular edema and leukocyte infiltration. The edema which was observed in heart, trachea and lungs could be due to uremia associated with renal lesions which resulted in vasculitis [35].

\section{Conclusion}

In Egypt; multiple variant IBV strains are circulating in broiler chicken flocks. Egyptian variant-2, IS/885/00 and IS/1494/06 or those with high similarities to these strains are still circulating and most of them are nephropathogenic. IBV causes severe damage to renal tissue which resulted in uremia which leads to vasculitis leading to damage of different organs.

\section{Acknowledgment}

We would like to acknowledge dr. Ali Zanaty. Gene analysis unit, Reference Laboratory of Veterinary Quality Control on poultry production (RLQP) for his help in this study.

\section{Conflict of interest}

None of the authors have any conflict of interest to declare.

\section{References}

[1] Cavanagh, D. (2003): Severe acute respiratory syndrome vaccine development: experiences of vaccination against avian infectious bronchitis coronavirus. Avian Pathol,32(6):567-582.

[2] Jackwood, M.W. and deWit, S. (2013): Infectious Bronchitis.In:Diseases of poultry. Editor-in-chief, David E. Swayne 
;associate editors, John R. Glisson ... [et al.]. $13^{\text {th }}$ ed. John Wiley \& Sons, Inc. p. 139-159.

[3] Yu, L.; Jiang, Y.; Low, S.; Wang, Z.; Nam, S.J.; Liu, W., and Kwangac, J. (2001): Characterization of three infectious bronchitis virus isolates from China associated with proventriculus in vaccinated chickens. Avian Dis,45(2): $416-424$.

[4] Ahmed, H.N. (1954): Incidence and treatment of some infectious viral respiratory diseases of poultry in Egypt.Ph.D.Thesis, Faculty of Veterinary Medicine, Cairo, Giza, Egypt.

[5] Abdel-Moneim,A.S.; Madbouly, H.M.; Gelb,J.R. and Ladman,B.S. (2002): Isolation and identification of Egypt/ Beni-Suef/01 a novel genotype of infectious bronchitis virus. Vet Med J, 50(4):1065-1078.

[6] El-Shafey, A. (2002):Current status of Infectious Bronchitis Disease in broiler at sharkia Governorate .MVSc.Thesis, Poultry Disease Dept., Fac. Vet. Med., Zagazig, Egypt.

[7] El-Shafey, A. (2008): Advanced study on Infectious Bronchitis of Chicken in Egypt. Ph.D.Thesis , Avian and Rabbit Mdicine Dept., Fac.of Vet. Med., Zagazig Uni., Egypt.

[8] Lebdah, M.A.; Amal , E.A., and El-Shafey , A.M. (2004): Infectious bronchitis virus infection among meat-type chickens in Sharkia Province. $4^{\text {th }}$ International Symposium on avian Corona and pneumovirus infections. Rauischholzhausen, Germany.

[9] Sultan, H.; Tantawi, L.; Youseif , A.I., and Ahmed, A. (2004): Urolithiathis in white commercial egg laying chickens associated with an infectious bronchitis virus.In $6^{\text {th }}$ Scientific Conference, Egyptian Veterinary Poultry Ass. Egypt.

[10] Seddik, M. (2005): Studies on infectious bronchitis in chicken. M V Sc.Thesis, Fac. Vet. Med., Alexandria University, Egypt.

[11] Sediek, M. (2010): Further Studies on infectious bronchitis in chickens. .Ph.D. thesis, Fac. Vet. Med., Alexandria Uni., Egypt.

[12] Mourad, A.A. (2012): Recent status of infectious bronchitis disease in broiler flocks in Egypt. MVSc.Thesis, Zagazig Uni., Egypt.

[13] Gelb, J.J. and Jackwood, M.W. (2008): Infectious Bronchitis. In: A Laboratory Manual for the Isolation, Identification and Characterization of Avian Pathogens, 5th ed. L. Dufour-Zavala, D.E. Swayne, J.R. Glisson, J.E. Pearson, W.M. Reed, M.W.Jackwood, and P. Woolcock, eds. American Association of Avian Pathologists, Kennett Square, PA. 146149.

[14] De Wit, J. (2000): Detection of infectious bronchitis virus. Avian Pathol,29(2):7193.

[15] Mahmoud, H.; Salama, E., and Abdel Latif, A. (2015): Use of monospecific antisera for differential diagnosis of classic and variant strains of infectious bronchitis virus. Int $\mathbf{J}$ Adv Res Biol Sci, 2(11):58-65.

[16] Office International Des Epizooties OIE,Terrestrial Manual(2013): Avian Infectious Bronchitis. Chapter 2.3.2, p. 443-455.

[17] De, Wit, J.S.; Cook, J. and van der Heijden, H. (2011): Infectious bronchitis virus variants: A review of the history, current situation and control measures. Avian Pathol, 40(3):223-235.

[18] Tamura, K.; Stecher, G.; Peterson, D.; Filipski, A., and Kumar, S. (2013) :Molecular Evolutionary Genetics Analysis version 6.0. Mol Biol Evol, 30(12):2725-2729.

[19] Ziegler, A.; Ladman, B.; Dunn, P.; Schneider, A.; Davison, S.; Miller, P.; Lu, H.; Weinstock, D.; Salem, M., and Eckroade, R. (2002):Nephropathogenic infectious bronchitis in Pennsylvania chickens 1997-2000. Avian Dis, 46(4): 847-858.

[20] Suvarna, S.K.; Layton, C. and Bancroft, J.D. (2013): Bancroft's Theory and Practice of Histological Technique. . 7th. Ed.,Churchill, Livingston, Elsevier, England. 
[21] Bande, F.; Arshad, S.S.; Omar, A.R.; Bejo, M.H.; Abubakar, M.S. and Abba, Y. (2016): Pathogenesis and Diagnostic Approaches of Avian Infectious Bronchitis. Adv Virol, vol. 2016,Article ID 4621659,11 Pages. doi:10.1155/2016/4621659

[22] Yudong, W.; YongLin, W.; Zichun, Z.; GenChe, F.; Yihai, J.; Xiange, L.; Jiang, D. and Shushuang, W.. (1998): Isolation and identification of glandular stomach type IBV (QX IBV) in chickens. Chin J Anim Quar, 15(1):1-3.

[23] Abdel-Moneim, A.S.; Afifi, M.A. and ElKady, M.F. (2012): Emergence of a novel genotype of avian infectious bronchitis virus in Egypt. Arch virol, 157(12):24532457.

[24] Selim, K.; Arafa, A.S.; Hussein, H.A. and El-Sanousi, A.A. (2013): Molecular characterization of infectious bronchitis viruses isolated from broiler and layer chicken farms in Egypt during 2012. Int Vet Sci Med, 1(2):102-108.

[25] Sediek , M.E. and Awad, A.M. (2014): Pathogenicity Assessment of Seven Variants of Infectious Bronchitis Virus Isolated from Commercial Broiler Chickens during 2013 in Egypt. J World's Poult Res, 4(3):64-74.

[26] Jose, D.F.; Lavinia, I.; Rossini, S.J.; Orbell, G.P.; Micheal, B.; Huggins, A.M.; Byron, G.M.; Silva, A. and Cook, J. (2000): Characterization of infectious bronchitis viruses isolated from out breaks of disease in commercial flocks in Brazil. avian Dis, 44:582-589.

[27] Zanaty, A.; Arafa, A.S.; Hagag, N. and ElKady, M. (2016): Genotyping and pathotyping of diversified strains of infectious bronchitis viruses circulating in Egypt. World J Virol, 5(3):125-134.

[28] Hassan, K.E.; Shany, S.A.; Ali, A.; Dahshan, A.H.; El-Sawah, A.A., and ElKady, M.F. (2016): Prevalence of avian respiratory viruses in broiler flocks in Egypt. Poult Sci, 95(6):1271-1280.
[29] Mahdavi, S.; Tavasoly, A.; Pourbakhsh, S. and Momayez, R. (2007): Experimental histopathologic study of the lesions induced by serotype 793/B (4/91) infectious bronchitis virus. Archives of Razi Institute, 62(1):15-22.

[30] Seifi, S. and Boroomand, Z. (2015): Ultrastructural study of the trachea in experimentally infected broilers with IBV serotype 4/91. Slovenian Vet Res, 52(1):15-21.

[31] Khataby, K.; Kichou, F.; Loutfi, C. and Ennaji, M.M. (2016): Assessment of pathogenicity and tissue distribution of infectious bronchitis virus strains (Italy 02 genotype) isolated from moroccan broiler chickens. BMC Vet Res, 12(1): 1.

[32] Toro, H.; Van Santen, V.; Li, L.; Lockaby, S.; Van Santen, E. and Hoerr, F. (2006): Epidemiological and experimental evidence for immunodeficiency affecting avian infectious bronchitis. Avian Pathol, 35(6):455-464.

[33]Bijanzad, P.; Momayez, R.; Bozorgmehrifard, M.H.; Hablolvarid, M.H. and Pourbakhsh, S.A. (2013): Experimental study on histopathological changes and tissue tropism of Iranian infectious bronchitis serotype 793/B-like virus in SPF chickens. J S Afr Vet Assoc, 84(1):1-7.

[34] Benyeda, Z.; Mato, T.; Süveges, T.; Szabo, E.; Kardi, V.; Abonyi-Toth, Z.; Rusvai, M., and Palya, V. (2009): Comparison of the pathogenicity of QX-like, M41 and 793/B infectious bronch-itis strains from different pathological conditions. Avian Pathol,38(6):449-456.

[35] Shelley, N.; Anthony, W.C., and Roger, P. (2006): Urinary System :In Pathologic basis of veterinary disease. $4^{\text {th. }}$ Ed., M.D. McGavin and J.F. Zachary. Elsevier Health Sciences. P: 642. 


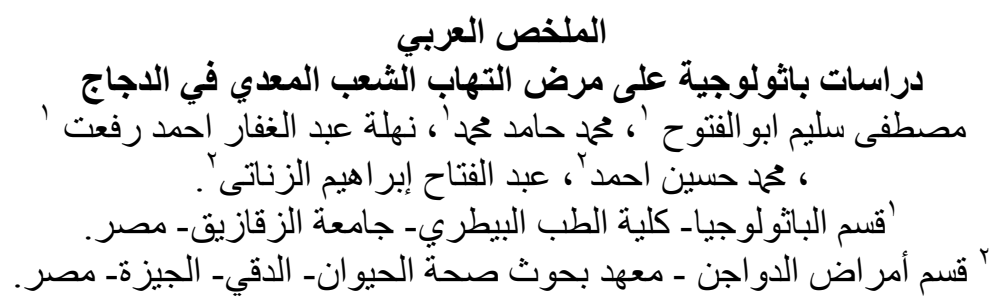

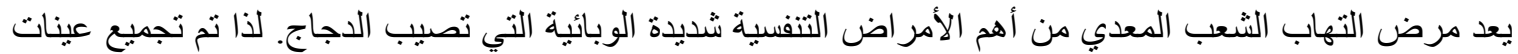

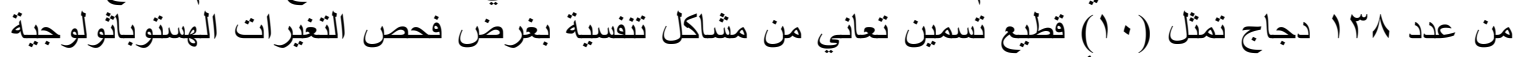

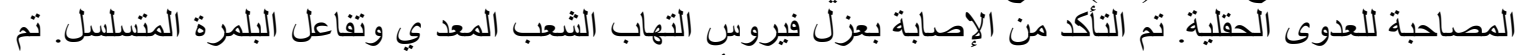

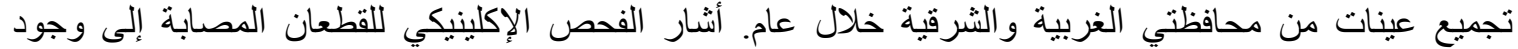

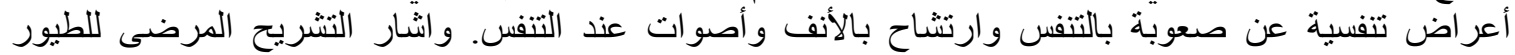

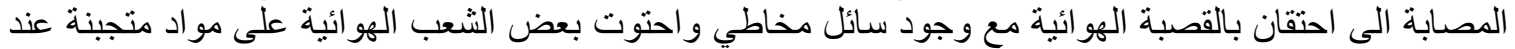

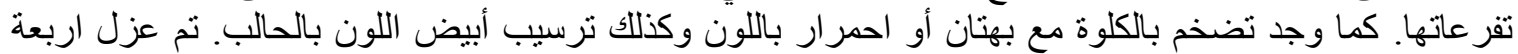

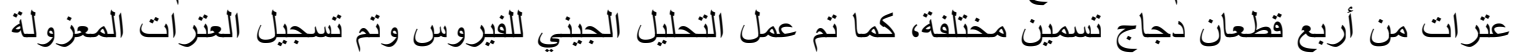

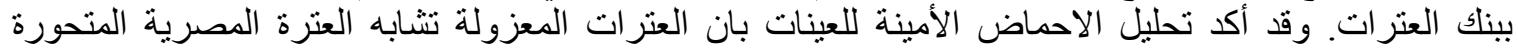

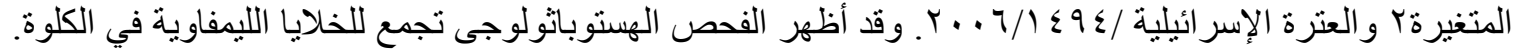

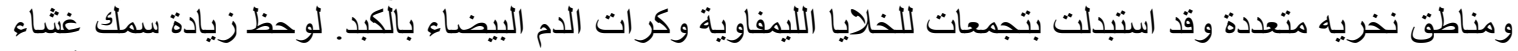

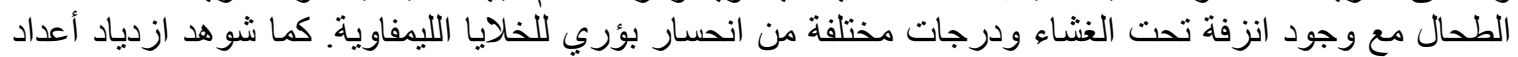

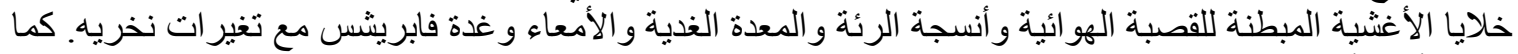

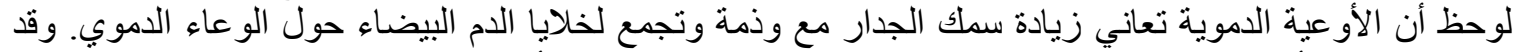

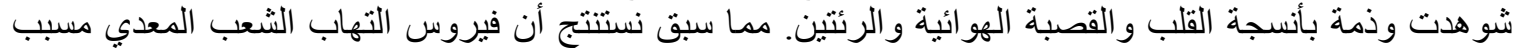

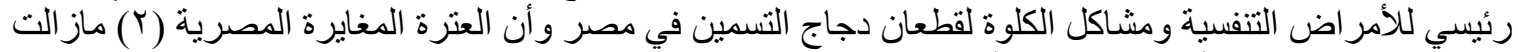
مستمرة وتسبب تدمير لأنسجة الكلية و الأعضاء المختلفة ألفان. 